\title{
Developing a theoretical model to improve the road network the a historical city in Iraq
}

\author{
Raeda Al-Daini ${ }^{1,2 *}$, Nina Danilina ${ }^{1}$, and Hayder A.A.Alaraza ${ }^{3,4}$ \\ ${ }^{1}$ Moscow State University of Civil Engineering, Yaroslavskoe shosse, 26, Moscow, 129337, Russia \\ ${ }^{2}$ Alfurat Al-Awsat Technical University, Iraq \\ ${ }^{3}$ RUDN University, Moscow, Russia \\ ${ }^{4}$ Kerbala University, Karbala, Iraq
}

\begin{abstract}
The expansion of transport networks as a result of urban growth with low coverage and low integration leads to low transport efficiency and inaccessibility. This leads to poor connectivity in ancient urban areas of the Iraqi provinces. Identifying the Iraqi provinces with the lowest transport efficiency by performing the supply-demand ratio of the master plan for the center of Iraq's provinces (for example, the city of Karbala) is an indicator of the availability and accessibility of transport in urban areas. Solutions to meet transport needs have not focused on improving road capacity and meeting demand by improving operational efficiency even in surrounding communities. In this research theoretical model measured the degree of accessibility of the road network in the city to assess the effectiveness of transport. It has been identified that closer the coefficient of supply-demand to the zero points will provide a comfortable level of service to all road users. This theoretical model evaluates and improves the impact of changing the function of the road network and using different modes of transportation taking into account religious factors, full range of demand control, system efficiency, and infrastructure capacity clarifications.
\end{abstract}

\section{Introduction}

Historical cities attract millions of people every year as tourists, and they consider very valuable in many aspects like historically, economically, and socially. These cities usually have difficulties especially in the transportation sector and congestion due to their small area, expensive land use, and old narrow street network. Therefore, enhancing the road network is driving the local urban to expansion to a certain point; however, on the other hand, it can also produce urban development [1]. The road network has experienced a rapid growth period over the last few decades and is widely studied in many countries. Based on the current traffic demand and road network data, statistical methods were used to analyze road network expansion [2, 3]. Yang Estimated the amount of traffic flow to model the changes in the road network to solve the problem of mixed network design [4].

$[\underline{5}, 6]$. [These studies investigated the growth of London's road network over a century. The Expansion road network from 1880 to 2013, by using different methods discovered growth

* Corresponding author: raedaka@gmail.com 
patterns as well as urban sprawl. Rui and Ban [7] analyzed the relation between the density of the road network and the form of land use and found that they were strongly correlated. Developing countries usually have short-term strategies to solve regional and urban planning problems of road networks. To solve short-term problems in cities, several measures are usually implemented; however, these measures do not lead to an increase in the efficiency of the transport system in the long term [8].

A study Addressed 8 Urban Planning Challenges during the 'Kumbh' festival in Allahabad city in India includes traffic and transport vehicular movement, parking, bus terminus and arrival points, railway station, pedestrian movement, local transportation[9]. The results of the influences of gathering at one time several hundred thousand believers at religious events in the old city can produce heavy traffic, employment of special trains and buses, and provision of parking places, logistic support, and other necessary facilities[10].

Based on the evaluated accessibility of the bus system in the city of Mashhad in Iran by using Hansen and Pooler model the researcher indicated that buses are the main use for public transportation $[11,12]$. The concept of supply and demand is important to economic theory and is widely applied in the field of transport economics. In the area of travel demand and the associated supply of transport infrastructure, the theories of supply and demand could be applied. Though, demand for transport is a derivative demand, not a necessity. That is, people do not travel for the sake of travelling, but to practice activities in different places [13]. Microsimulation models have addressed day-to-day and within-day variability in both demands and supply dynamic conditions for real-time transport strategies in automated highway and responsive traffic signal control systems[ 14]. The dynamic panel model is applied in Tunisian research determined the key factors affecting the decision to travel by public transport and clarifies how the use of these means fits the mobility approaches [ 15]. The proposed Supply-Demand model to compare 7 sub-models: population, economic development, number of vehicles, environmental influence, travel demand, transport supply, and traffic congestion. using the data from Dalian, China. The authors analyzed the impacts of different policy scenarios on urban development and transportation system [ 16].

Developments of old Iraqi cities require improvement of the road network which is considered the backbone of the structure of the city. This research presents a theoretical model to evaluate and improve the transportation network in historical cities. The research used Karbala as a case study as it is one of the most important cities in Iraq.

\section{Methods and materials}

Road density is an important criterion; it is a quantitative method for evaluating the services provided by a road. It also provides an indication of the level of availability or scarcity within a city and is also reflects the economic development of the district. The measurement of road density is determined by the length of roads per unit area or unit population. Transport professionals usually assess the efficiency of transportation networks using two concepts: level of service (LOS) and capacity. These two definitions reflect the characteristics of the transport facility and the supply is provided to the road users [17]. The more the road network is fairly distributed, the better the network can cover the needs of the population, while a decrease in density means that many areas of the city are deprived of network services. This study used the quantitative method and coefficient of demand and supply. The process of creating the theoretic model is shown in Fig. 1. 
Determining factors and parametres of the Roadstreet-network of the city
State the city into four zones and set the criteria for every zone
Coefficient of demandsupply for every zone and every transport mode

Fig. 1. Process of main steps to create the theoretic model

In this research the analysis parameters were:

1) City area and planning zones

2) Accessibility of its central planning part;

3) Road Street Network (RTN) intensity, capacity, and load

To improve the city, 4 zones were determined as shown in Fig. 2 according to the factors that have been described in Table (1).

Table 1. Description of the factors that determined the Road-street-network for different user groups

\begin{tabular}{|c|c|c|c|c|}
\hline \multicolumn{2}{|c|}{$\begin{array}{l}\text { Factors that determine the } \\
\text { capacity of the RTN }\end{array}$} & \multicolumn{2}{|r|}{ Factor estimation parameters } & Units \\
\hline \multirow{4}{*}{$\mathrm{X} 1$} & \multirow{4}{*}{$\begin{array}{l}\text { Factor of the city's } \\
\text { planning structure }\end{array}$} & $\mathrm{x} 11$ & Functional zoning of the territory & - \\
\hline & & $\mathrm{x} 12$ & $\begin{array}{l}\text { Planning zoning of the territory (central, } \\
\text { middle, provincial zones) }\end{array}$ & - \\
\hline & & $\mathrm{x} 13$ & $\begin{array}{l}\text { The accessibility of the points of attraction } \\
\text { of the population }\end{array}$ & minut \\
\hline & & $\mathrm{x} 14$ & Location of historical zones & - \\
\hline \multirow{3}{*}{$\mathrm{X} 2$} & \multirow{3}{*}{$\begin{array}{l}\text { Transport service } \\
\text { factor }\end{array}$} & $\mathrm{x} 21$ & Structure RTN & \\
\hline & & $\mathrm{x} 22$ & $\begin{array}{l}\text { Capacity of RTN ( personal transport, } \\
\text { Public transport, bicycles, pedestrians) }\end{array}$ & unit./hour \\
\hline & & $x 23$ & The density of RTN & $\mathrm{KM} / \mathrm{km} 2$ \\
\hline \multirow{3}{*}{$\mathrm{X} 3$} & \multirow{3}{*}{$\begin{array}{c}\text { The factor of } \\
\text { transport mobility of } \\
\text { the population }\end{array}$} & $\mathrm{x} 31$ & Population size & $\begin{array}{l}\text { Thousand. } \\
\text { person }\end{array}$ \\
\hline & & $\mathrm{x} 32$ & $\begin{array}{l}\text { Mobility of the permanent population } \\
\text { (general and transport) }\end{array}$ & $\begin{array}{l}\text { Move. / hour } \\
\text { peak } \\
\text { Move. / day }\end{array}$ \\
\hline & & $\mathrm{x} 33$ & $\begin{array}{l}\text { Mobility in the city during religious } \\
\text { holidays (general and transport) }\end{array}$ & $\begin{array}{l}\text { Move. / hour } \\
\text { peak } \\
\text { Move. / day }\end{array}$ \\
\hline
\end{tabular}

Based on the previous studies and the determination of the parameters, the theoretical model of zoning of Road-street-network was developed as shown in Fig.4, which included:

1. Develop a pedestrian zone in the historical center of the city;

2. Creating accessibility zones for the pedestrian in a transport hub that decreases in traffic volume on the road;

3. Development of public transport systems that allowed regulation of access to the road network;

4. Intermodal transport and transfer hubs installed including moving population mobility;

5. Management of urban parking lots. 
It is been revealed that several major cities around the world that as capacity increases, demand often needs to be raised at a comparable pace, otherwise transport users do not have net travel time benefits in the long term, and society suffers from the impacts of expensive road bills and environmental desolation. Sasser (1976) suggested two fundamental methods that involve "chase-demand" and the policy of "level-capacity" [18].

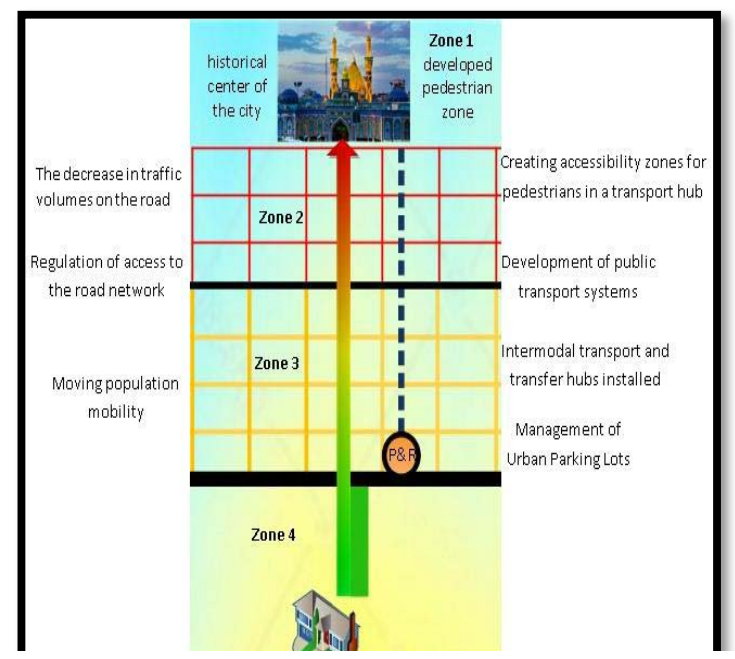

Fig. 2. "Zoning" model as part of the Road-Street- Network

The capacity is adjusted to match demand in the first strategy and the capacity is kept constant in the second one and demand is managed. Balancing capacity and demand are essential to the success of any operation or transaction [19].

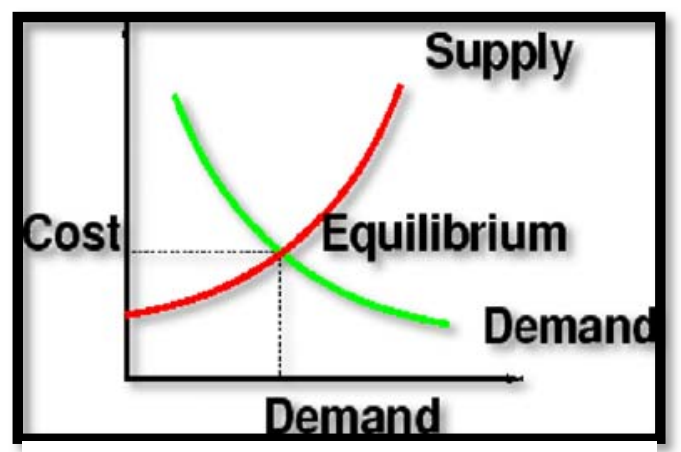

Fig. 3. Balance of supply and demand

The concept of equilibrium is central to the analysis of supply and demand. It is common practice to plot a supply and demand curve as a function of cost and the intersection is then contrived at the equilibrium point as shown in Fig.3. In other words, the supply function will answer the question of what the system's service level will be if the estimated demand is uploaded to the system. The most common supply function is the channel transit time function, which relates the channel volume and transit time. When the total supply is less than the total demand, it is still possible to create a balanced to solve the transportation problem [20]. 
Mobility usually takes place over fixed capacity infrastructures, which translates into the availability of transport. The transport system consists of two main components: the demand for travel and the supply of transport [21, 22]. The supply of transport is the capacity of transport infrastructures and modes for a given duration within a geographical region. Experts typically express their capabilities in terms of infrastructure (capacity), facilities (frequency) and networks, (coverage). The need for travel is a demand and the need for mobility. It can be expressed as the number of people, volume, or tons per unit of time and space, similar to transport supplies [22]. The increasing transportation demand creates more and more mobility-related problems.

The mathematical model was used in this research is the coefficient of demand /supply ratio [19]. Vuchic States that the criteria to determine the efficiency of roads by finding the ratio of demand/supply. In this work unites were used are the cars/hour, people /hour, bicycle/hour, and bus/hour [24], the ratio should range $(0,1)$.

$$
K=\frac{V}{C}
$$

\section{Where:}

\section{K: Coefficient of accessibility}

\section{V: Demand, C: Supply}

Where $\mathrm{V}$ is the demand in the urban area of the study community, $\mathrm{C}$ is the supply of the roads. The value $\mathrm{K}$ is the combined value that will be within the range $(0,1)$. If there are no enough roads in the area, the value will be (1) if $\mathrm{K}$ minimize and closer to the number 0 , refers to more connection of the road network and the more coverage of the area, therefore is better the lower ratio of the coefficient.

\section{Implementation}

Many of the transportation infrastructure plans that exist in most Iraqi cities have been focused on private vehicle mobility, reducing short-term capital costs, and have neglected or less addressed efficiency social and environmental aspects.

Karbala city in Fig.4, which considers a tourist attraction place for decades, did not have a rational plan to improve the road network (supply) that meets rising demand. The city of Karbala increased in the number of visitors, especially on the days of the weekend, which reaches more than 60 thousand vehicles per day and decreases to the equivalent of 55 thousand vehicles on a normal day.

The arrival pattern of visitors is one of the important factors that contributed to the level of transportation demand during the event, and peak days as the number of visitors to the city reaches $(726,991$ visitors/day) on foot and (53,200 thousand vehicles /day). According to the Communications and Information Technology department, Al Kafeel Center for information and statistical studies [23], the numbers of visitors were 15,229,955 in 2019 with an average of 6-10 hours staying in the city. While in 2020 the number of visitors was $14,553,308$ visitors during the pandemic of Coronavirus. 

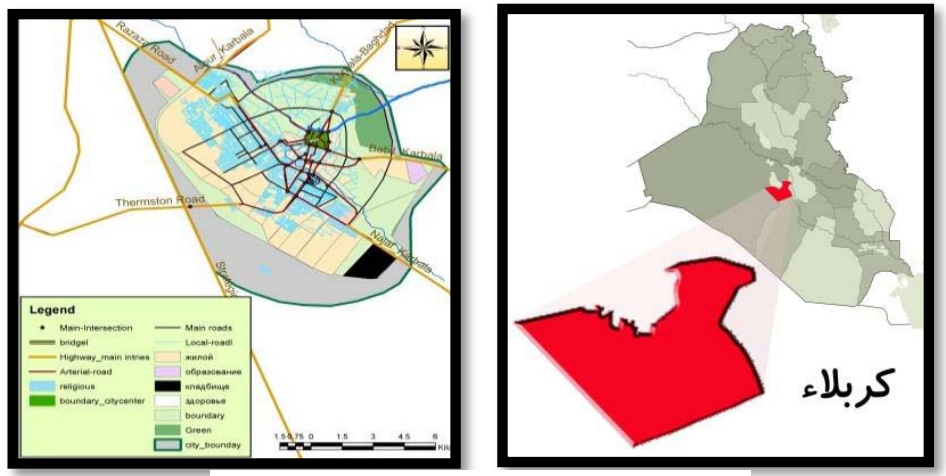

Fig. 4. Province and city of Karbala

According to the factors anu paianums m ı avic 1, un ıvau nutwork of Karbala city has been assessed and stated into 4 zones. Fig. 5 shows the implementation of the theoretical model as an example of the city Karbala.
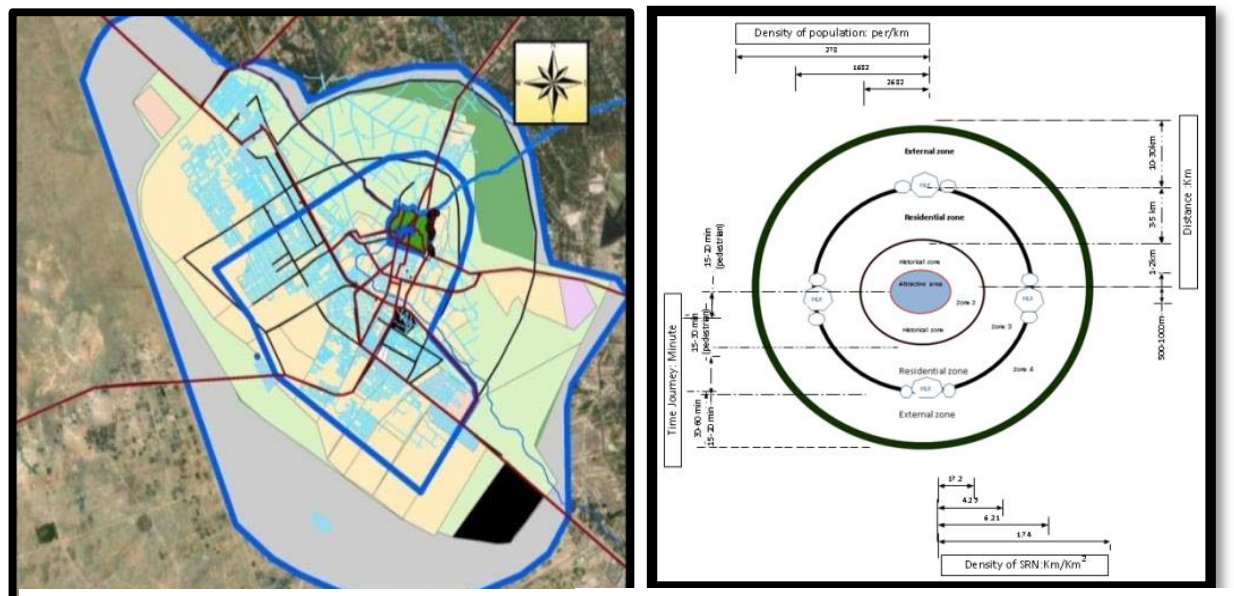

Fig. 5. Zoning of the city of Karbala

Fig. 6. Implementation theoretical model for Karbala city

Table 2. description of zones by criteria

\begin{tabular}{|c|c|c|c|c|}
\hline Zone & Distance: Km & Travel time: $\min$ & Density $\mathrm{km} / \mathrm{km}^{2}$ & Density person $/ \mathrm{km}$ \\
\hline Zone1 & $0.500-1.00$ & 15-20 (Walking) & 17.2 & _ \\
\hline Zone 2 & $1-2$ & 15-30 (Walking) & 4.25 & 2682 \\
\hline Zone 3 & $3-5$ & $15-20$ & 6.21 & 1682 \\
\hline Zone 4 & $10-30$ & $30-60$ & 1.74 & 273 \\
\hline Sum & - & - & 3.36 & 1226 \\
\hline
\end{tabular}

As a result of the analysis of the city of Kerbala, 4 zones have been identified with homogeneous transport and planning conditions. The description of the 4 zones is in Table 2 and Fig.6, all the results of indicators are unsatisfactory as shown above.

After identifying the 4 zones, the mathematical model was used with the data were provided from multiple sources, department Al Kafeel Center for information and statistical studies, department of urban planning at the administration of Karbala city, and statistical 
calculations made using the ArcGIS10.x software package and Microsoft Excel. The coefficients of demand-supply were calculated for every transport mode in every zone.

\section{Results}

The results show that there is a big problem of congestion in the city and there is a need to solve these problems with a long-term solution.

Table 3 and Fig. 7 show four zones and their coefficient of accessibility to the transport network of the city with type of mobility on regular days and holiday days.
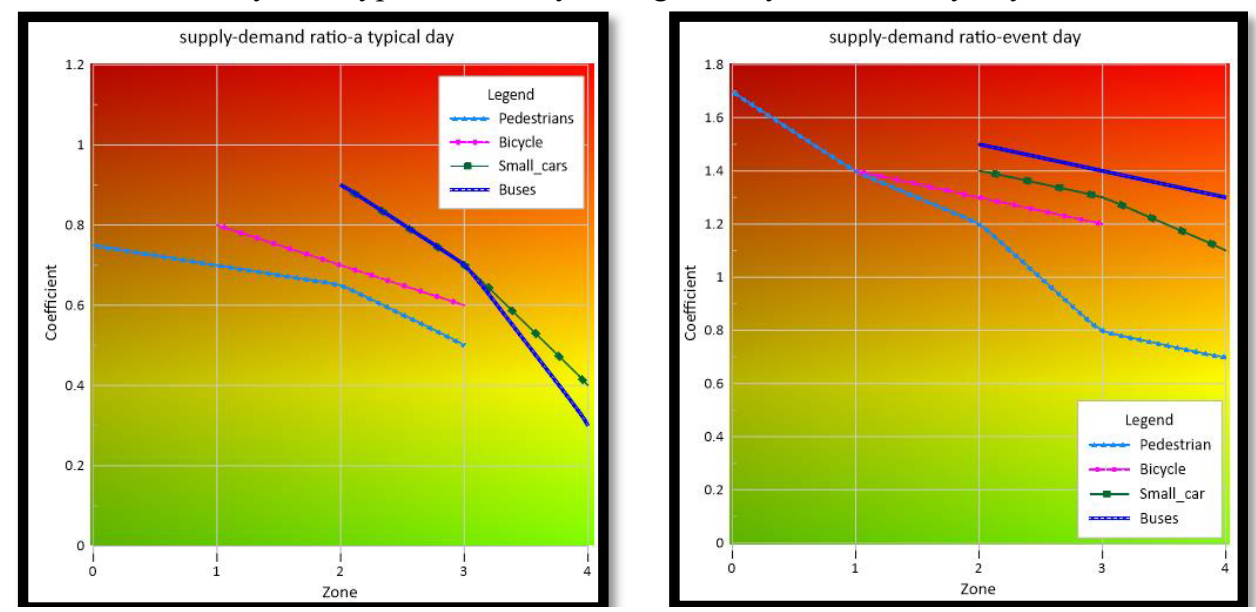

Fig. 7. Supply-demand ratio for different transportation mode in 4 zones-typical and event day

Fig. 7 shows that the coefficient for the regular day for zone one pedestrian was close to 1 . Zone 2 coefficients were $0.8-0.7$ for pedestrian and bicycle, while zone 3 has $0.9-0.5$ for

Table 3. Supply-demand ratio for different modes of transport for 4 zones (typical and event day)

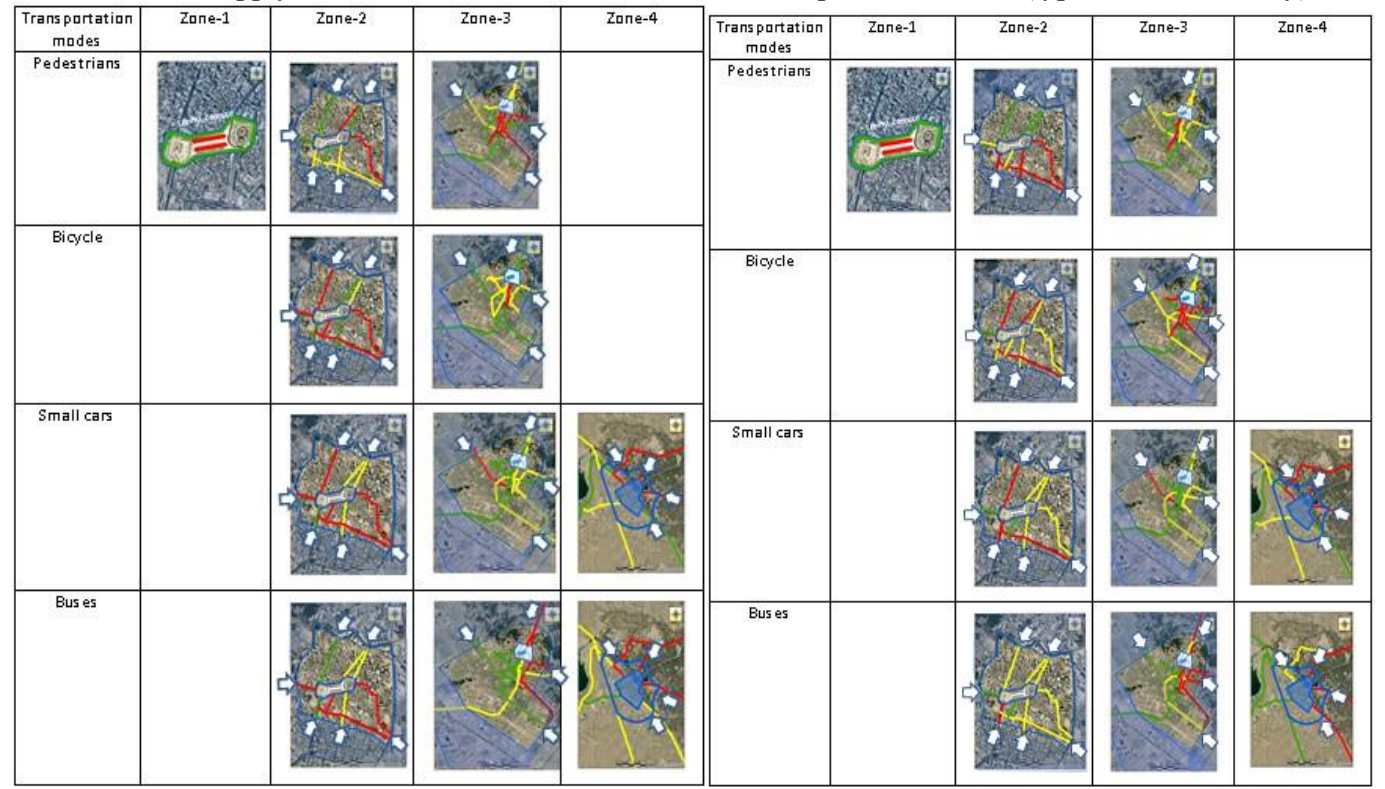

pedestrian, bicycle, public transport, and small cars. Zone 4, the coefficients were between 
0.5-0.3 for both buses and small cars. Also, Fig. 7 shows that the coefficient for holiday for zone one pedestrian was 1.7. Zone 2 coefficient was between 1.4-1.2 for pedestrian and bicycle, while zone 3 ranged 1.5-0.8 for pedestrian, bicycle, public transport, and small cars. In zone 4 the coefficients were between 1.4-0.8 for buses, small cars, and pedestrians. This indicates that the road network is not efficient as the coefficients reached or exceed 1 which results in a very crowded area for each transport mode.

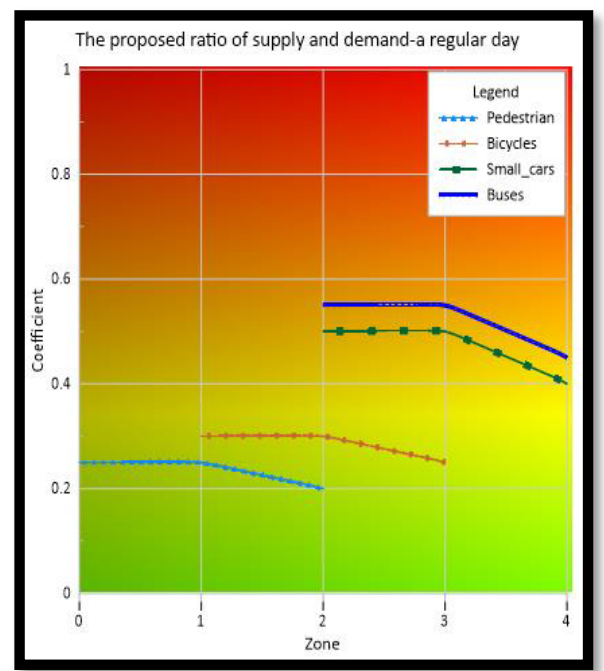

Fig. 8. Proposed supply-demand ration in 4 zones-normal day

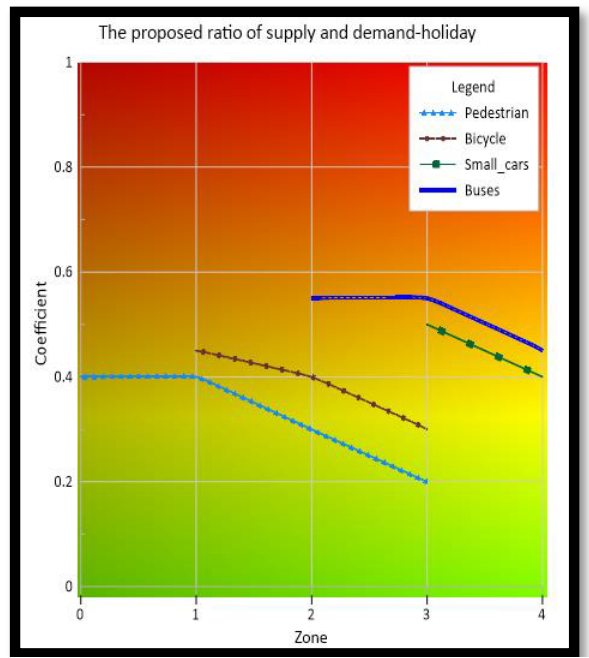

Fig. 9. Proposed supply-demand ration in 4 zones-event day

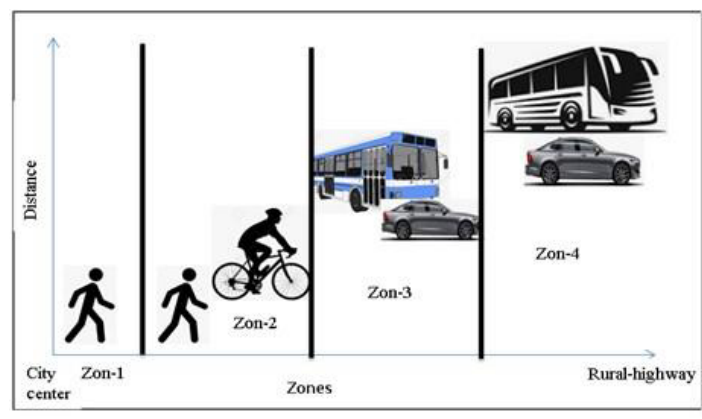

Fig. 10. Proposed type of transportation mode in 4 zones-normal day

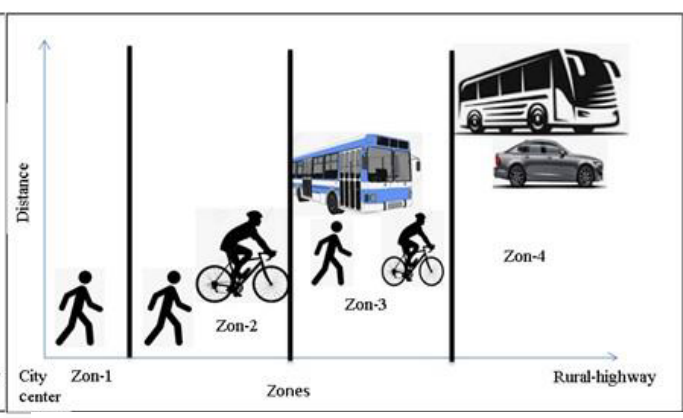

Fig. 11. Proposed type of transportation mode in 4 zones-event day

Some of the main strategies to be considered when developing cities: pedestrian-only zones in areas with heavyweight pedestrian traffic, special lanes for buses and bicycles, which are sufficiently protected from car traffic, and more road infrastructure maintenance rather than the construction of new infrastructure.[24,25] Also Parking and Ride (P \& R) is an effective system of achieving collaboration between cars and transit in a sustainable urban transit network planning with high-level operating service [26].

As stated earlier "The needs to reduce travels and creates streets and pedestrian areas in the central areas and encourages the movement of people by foot, bicycle or public transport and design the streets, corridors, and works attractively for everyone to enjoy". Thus, to 
achieve this goal the suggested zones arranged into different types of mobility as shown in Fig. 8 and Fig. 10 for the regular days. Zone 1 just for pedestrian, zone 2 for pedestrian and bicycle, zone 3 has 3 modes of transport (bicycle, cars, and public transport) with priority to the bicycle and public transport, where zone 4 has just two modes of transport private car and public transit which can results in coefficient less than 0.6. Fig. 9 and Fig.10 shows the distribution of mobility in holidays where zone 1 just for pedestrian zone 2 for pedestrian and bicycle, zone 3 has 3 mode of transport (pedestrian, bicycle, and public transit) where zone 4 has just two modes of transport privet cars and public transport and that will result in coefficient less than 0.6. The closer the coefficient of demand and supply to the zero points will provide a comfortable level of service to users-cars, passenger transport, cyclists, and pedestrians.

\section{Conclusion}

The theory of supply and demand ratio is a reasonable method to create a theoretical model to organize the city's street and road network with the best performance and comfortability of road users, taking into account its religious function. The researcher found the following conclusions:

1. Organize Karbala city into four zones may highly enhance the efficiency of the street road networks and improve the performance of transport users.

2. The coefficients of all transportations modes in the zones in Karbala city was found to be close to 0.9 in weekday.

3. Weekend and special events in the city have very high coefficients that exceed 1.0

4. The First zone in the central area of historical sites should be used for pedestrian traffic with free-walking. Improve the pedestrian area so that it supports the presence of safe lanes and sidewalks and easy to reach.

5. Connecting the central area to other areas by pedestrian streets and secondary public places.

6. Create a sustainable transport hierarchy that supports pedestrians, public transport, high-capacity cars, and low-capacity cars in descending order of priority, Shifting transportation mode from one to another may result in the reduction of travel time and increase the quality of transport services [22].

7. Using the model will result in a modern and efficient transport system based on the balance and integration of multiple modes of transport, connecting the different growing areas of the city using the public transport of high quality, and meeting the needs of the tourist.

\section{References}

1. R. Cervero, Road expansion, urban growth, and induced travel: A path analysis, J. Am. Plan. Assoc, 69, Pp.145-163, (2003)

2. P. Parthasarathi, D.M. Levinson, R. Karamalaputi, Induced demand: A microscopic perspective, Urban Stud, 40, Pp.1335-1351, (2003)

3. Levinson, D.; Karamalaputi, R. Induced supply: A model of highway network expansion at the microscopic level, J. Transp. Econ. Policy, 37, pp. 297-318. (2003)

4. H.Yang, M.G.H. Bell, Models and algorithms for road network design: A review and some new developments, Transp. Rev, 18, pp. 257-278 (1998)

5. M. Batty, Cities as systems of networks and flows. In In the Post-Urban World, Routledge: London. UK, Pp. 56-69, 2017

6. P. Sulis, E. Manley, C. Zhong, M. Batty, Using mobility data as proxy for measuring urban vitality, J. Spat. Inf. Sci, 16, pp. 137-162. (2018) 
7. Y. Rui, Y. Ban Exploring the relationship between street centrality and land use in Stockholm. , Int. J. Geogr. Inf. Sci, 28, pp.1425-1438., (2014)

8. В. Р. Вучик. Транспорт в городах, удобных для жизни, Территория будущего; Москва; ISBN 978-5-91129-058-0. (2011).

9. H. Chadha, P. Onkar, Changing Cities in the Perspective of Religious Tourism - A case of Allahabad, Procedia Technology, 24, pp.1706 - 1713( 2016 )

10. G. Rinschede, Forms of religious tourism, Annals of Tourism Research, 19, pp. 51-67, (1992)

11. M. R Rahnamma, Bus accessibility planning in Iran: the case of Mashhad, WIT Transactions on The Built Environment, 96, doi:10.2495/UT070351.(2007)

12. V. Vakili, AR. Zarifian, and M. Rezaiyan Predictors of public transportation in Mashhad: A population-based study/, Journal of Education and Health Promotion, ;7:5. DOI: 10.4103/jehp.jehp_44_17. (2018)

13. M. Mahmood, A. Mohammad, S. Akhter, Traffic Management System and Travel Demand Management (TDM) Strategies, Asian Journal of Management and Humanity Sciences, 4, No. 2-3, pp. 161-178. (2009).

14. R. Liu, D. Van Vliet, and D. Watling, Microsimulation models incorporating both demand and supply dynamics, Transportation Research A: Policy and Practice, 40, no. 2, pp. 125-150. (2006)

15. M. Daldoul, S. Jarboui, A. Dakhlaoui, Public transport demand: dynamic panel model analysis, Transportation, Vol.43(3), pp.491-505. DOI:10.1007/s11116-015-9586-1. (2016)

16. J. Wang, , H. Lu, H. Peng, System dynamics model of urban transportation system and its application, Journal of Transportation Engineering and Information Technology, 8(3), pp.83-89. DOI:10.1016/s1570-6672(08)60027-6. (2008)

17. T. K. Beverly, Transportation Engineering A Practical Approach to Highway Design, Traffic Analysis, and Systems Operations, McGraw-Hill Education. (2019)

18. E. Sasser, Match Supply and Demand in Service Industries, Harvard Business Review, 54(5), 44-51. (1976).

19. T. May, Urban Transport Policy Instruments (Special Issue), Transport Policy, 10(3), 157-164. (2003).

20. Ch. Wu, Y. Pei and J. Gao, Model for Estimation Urban transportation Supply-Demand Ratio, Hindawi Publishing Corporation Mathematical Problems in Engineering, Vol.2015. ID 502739, 12 pp, doi.org/10.1155/2015/502739 (2015).

21.J. P. Rodrigue, C. Comtois, and B. Slack, The Geography of Transport Systems Third edition, Routledge, (2017).

22. V.A. Profillidis. and G.N. Botzoris, Modeling of Transport Demand Analyzing, Calculating and Forecasting Transport Demand, Elsevier Inc. ISBN: 978-0-12811513-8. (2019)

23. Press of the Abbass Sanctuary in Karbala, Communications and Information Technology department, Al Kafeel Center .(2020).

24. D. Pojani and D. Stead Sustainable Urban Transport in the Developing World: Beyond Megacities, Sustainability (Switzerland), Vol.7 (6): 7784-7805, (2015).

25. F. Adarkwa Assessing the Impacts of Road Capacity Improvements on Project Communities: A Case Study of the National Highway 1 ( N1-Highway) Accra, ProQuest Number: 27629453. (2019).

26. K. Lu, B. Han and X. Zhou Smart Urban Transit Systems: From Integrated Framework to Interdisciplinary Perspective, Urban Rail Transit, Vol. 4 (2): 49-67. (2018). 